Research Article

\title{
In Situ Monitoring of the Long-Term Settlement of High-Fill Subgrade
}

\author{
Liang Jia $\mathbb{D}^{1},{ }^{1}$ Jian Guo, ${ }^{2}$ and Kai Yao $\mathbb{D}^{3}$ \\ ${ }^{1}$ Associate Professor, College of Civil Engineering, Lanzhou University of Technology, Lanzhou 730050, China \\ ${ }^{2}$ Master Student, College of Civil Engineering, Lanzhou University of Technology, Lanzhou 730050, China \\ ${ }^{3}$ Research Fellow, Department of Civil and Environmental Engineering, National University of Singapore, Singapore, 117576 \\ Correspondence should be addressed to Kai Yao; yaokai@u.nus.edu
}

Received 16 July 2018; Revised 16 August 2018; Accepted 26 August 2018; Published 30 September 2018

Academic Editor: Venu G. M. Annamdas

Copyright (c) 2018 Liang Jia et al. This is an open access article distributed under the Creative Commons Attribution License, which permits unrestricted use, distribution, and reproduction in any medium, provided the original work is properly cited.

\begin{abstract}
Monitoring the settlement of high-fill subgrade plays a significant role in maintaining the service quality of highways. To investigate the postconstruction settlement of high-fill subgrade under gravity stress and vehicle loads, in situ monitoring was carried out on the Lanzhou-Yongjing highway. Single-point settlement meters were buried in various depths under the driveway and road shoulder. The evolution of settlement with time and space was analyzed. The results show that the settlement of the road shoulder is greater than that of the driveway; the settlement of the subgrade increases with time and tends to be stable after 1 year; the vehicle loads have no big effect on the settlement of the subgrade; the exponential model can be adopted to predict the settlement of the Lanzhou-Yongjing highway accurately.
\end{abstract}

\section{Introduction}

High subgrade more than $4 \mathrm{~m}$ is commonly adopted in China [1], usually leading to big subgrade settlement. Severe settlements of the subgrade will cause many engineering problems, such as subgrade failure and pavement cracks (e.g., [2-4]). Therefore, the monitoring of the subgrade settlement is of great significance to ensure the safety and stability of the subgrade. Extensive researches have been conducted to investigate the settlement of the high-fill subgrade by in situ monitoring or theoretical analysis. The evolution of the settlement has been grossly investigated (e.g., [5-10]), while prediction models have also been developed for capturing the development of the subgrade settlement (e.g., [11-13]). However, each study is based on their own soil type so that the availability settlement prediction model may be limited, as the heterogeneous filed sediments consist of various soil types interlayered at random $[14,15]$. Although Terzaghi's conventional linear onedimensional model [16] can be adopted to predict the ultimate primary consolidation settlement for the foundation, the in situ consolidation is a three-dimensional problem with varying coefficients of consolidation [15, 17]. In addition, the unsaturated state of the subgrade will pose more difficulties for accurate settlement prediction of the subgrade [18]. This study is to investigate the evolution of the subgrade settlement of the Lanzhou-Yongjing highway (Figure 1), for a better understanding of the deformation characteristics of the high-fill subgrade. Single-point settlement meters were used for the long-term monitoring of the postconstruction subgrade settlement. Moreover, the prediction models were also proposed based on the measured settlement data.

\section{In Situ Monitoring}

2.1. Site Condition. For the Lanzhou-Yongjing highway, the section from $24+160 \mathrm{~km}$ to $25+838 \mathrm{~km}$ was with high-fill subgrade. The settlement meters were set up from 24 $+400 \mathrm{~km}$ to $24+405 \mathrm{~km}$, which were semifilling and semiexcavating subgrades (Figure 2(a)). On the right side of the subgrade, a steep slope was there while flood drainage was on the left side of the subgrade. The materials excavated from the slope were used to fill the subgrade. The maximum filling height of this section was $18.3 \mathrm{~m}$. From $0-12.3 \mathrm{~m}$ height, the 


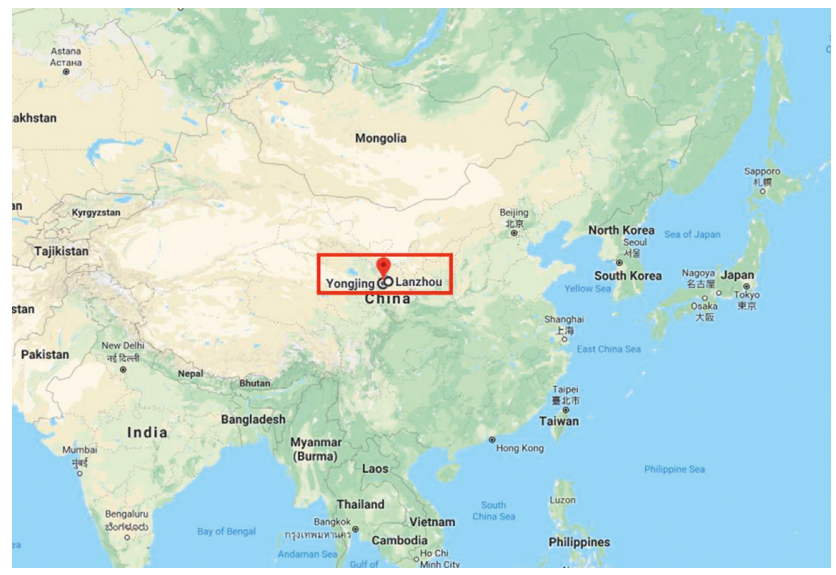

Figure 1: Location of the Lanzhou-Yongjing highway in China (Map Data @ 2017 Google).

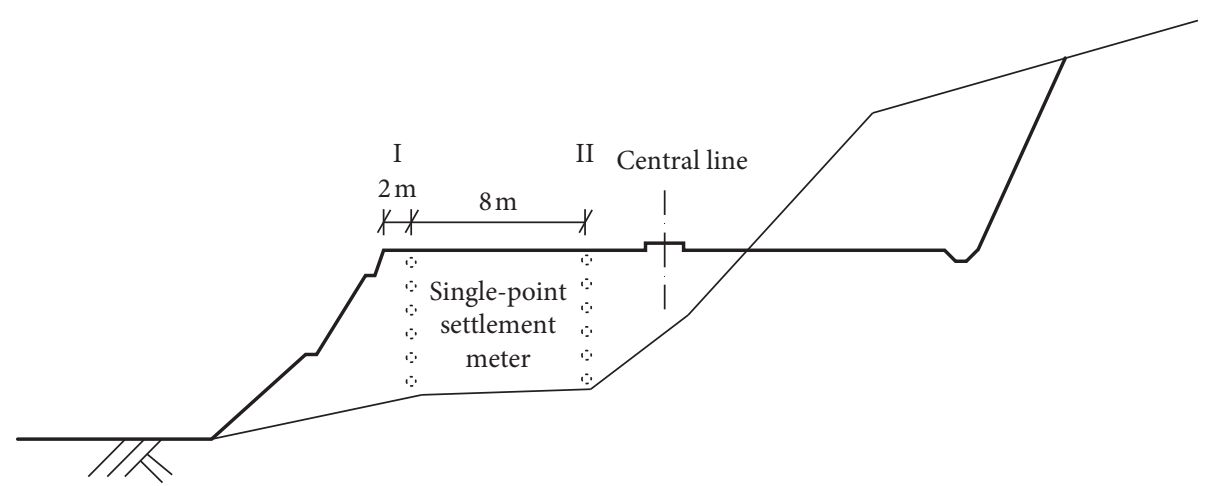

(a)

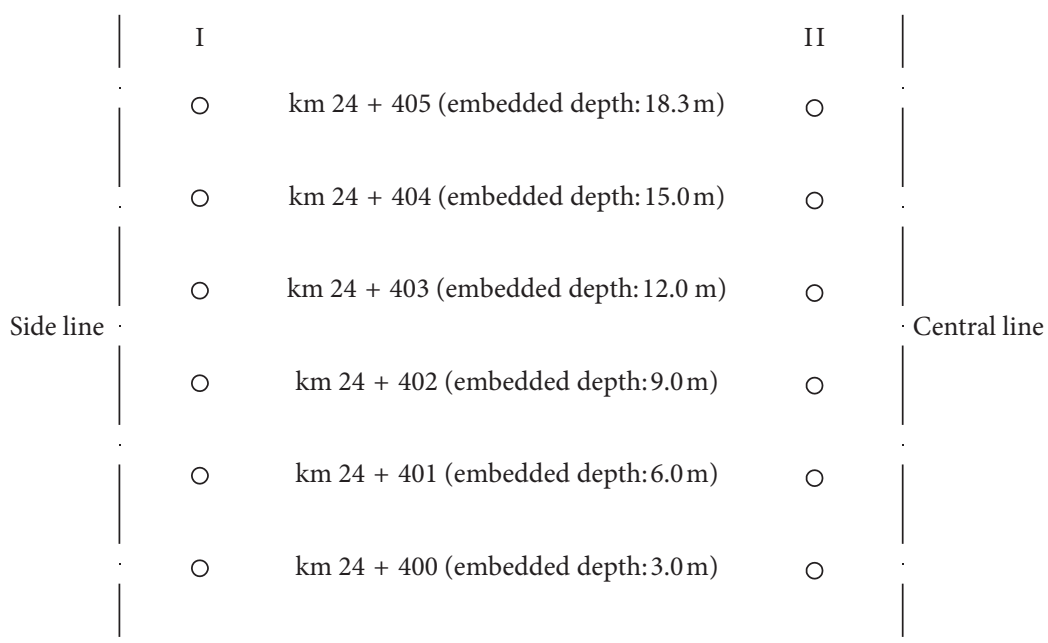

(b)

FIGURE 2: (a) Layout profile of the single-point settlement meters. (b) Planar graph of the single point settlement meters.

subgrade was filled with loess. From $12.3-16.1 \mathrm{~m}$ height, it was filled with a sandy pebble. From 16.1-18.3 m height, it was filled with gravel. The physical and mechanical properties of the subsoils are shown in Table 1.
2.2. Settlement Monitoring. Single-point settlement meters were adopted to monitor the long-term settlement of the subgrade. The measurement range of the single-point settlement meter is $200 \mathrm{~mm}$ while its sensitivity is 
TABle 1: Physical and mechanical parameters of subsoil.

\begin{tabular}{|c|c|c|c|c|c|c|c|}
\hline Soil type & Thickness (m) & $\begin{array}{c}\text { Moisture } \\
\text { content (\%) }\end{array}$ & $\begin{array}{l}\text { Gravity } \\
\left(\mathrm{kN} \cdot \mathrm{m}^{3}\right)\end{array}$ & $\begin{array}{l}\text { Void } \\
\text { ratio }\end{array}$ & $\begin{array}{c}\text { Compression } \\
\text { coefficient }\left(\mathrm{MPa}^{-1}\right)\end{array}$ & $\begin{array}{l}\text { Compression } \\
\text { modulus (MPa) }\end{array}$ & $\begin{array}{l}\text { Bearing capacity } \\
\text { eigenvalues }(\mathrm{kPa})\end{array}$ \\
\hline Loess & 10.4 & 8.5 & 14.1 & 0.96 & 0.21 & 6.2 & 150 \\
\hline Loess & 4.8 & 16.5 & 14.9 & 0.89 & 0.23 & 7.6 & 180 \\
\hline Pebble & 3.3 & 21 & 24.8 & 1.15 & - & - & 400 \\
\hline Mudstone & - & - & 25.3 & - & - & - & 600 \\
\hline
\end{tabular}

$0.05 \mathrm{~mm}$. The layout of settlement meters is shown in Figure 2. It can be seen that, for both the road shoulder and driveway, 6 layers of settlement meters were embedded. The embedment depth is reflected in Figure 2(b), which were $3 \mathrm{~m}, 6 \mathrm{~m}, 9 \mathrm{~m}, 12 \mathrm{~m}, 15 \mathrm{~m}$, and $18.3 \mathrm{~m}$, respectively. The schematic diagram of the single-point settlement meter is shown in Figure 3. The settlement meter consists of a settlement plate, an electrical displacement sensor, a measuring rod, a metallic hose, an anchor head, an extension bar, and a bottom anchor head. As the ground settles with the placement of fill, the settlement plate moves downward. The inductance of the coils of an electrical displacement sensor changes according to the motion of the settlement plate. Then, the variation of inductance is reflected by a frequency signal to a data logger. Figure 4 illustrates the setup process of single-point settlement meters. Figure 4(a) shows the boreholes with a diameter between $90 \mathrm{~mm}$ and $127 \mathrm{~mm}$ driven to the design depth for the setup of single-point settlement meter. In Figure 4(b), the bottom anchor was connected with the extension bar, and then cement slurry was poured into the ground through the PVC tube. Figure 4(c) states the process of connecting other extension bars until it reaches the designed depth for the embedment of the settlement plate. In Figure 4(d), sand was adopted for backfilling the hole, and the settlement plate was fixed. Figure 4(e) shows the automatic data collection system connecting with the single-point settlement meters, which could collect the settlement data by the CMNET wireless transmission network [19]. And the settlement data can be saved automatically once every 5 days.

\section{Test Results and Analysis}

3.1. Test Results. The variation of a settlement with time for different depths of the road shoulder is shown in Figure 5, while the variation of a settlement with time for different depths of the driveway can be found in Figure 6. It can be seen from Figure 5 that the settlement of the subgrade tends to be stable after around one year. For various layers of the subgrade, the top part of the subgrade shows a bigger settlement, and the maximum settlement can be observed on the top of the subgrade. This is due to that the subgrade itself has some amount of compression under the self-weight. The Lanzhou-Yongjing highway was operated for traffic from 1 Oct 2015, but no significant growth of settlement can be identified after that time. This is due to that the LanzhouYongjing highway was mainly built for the tourism service,

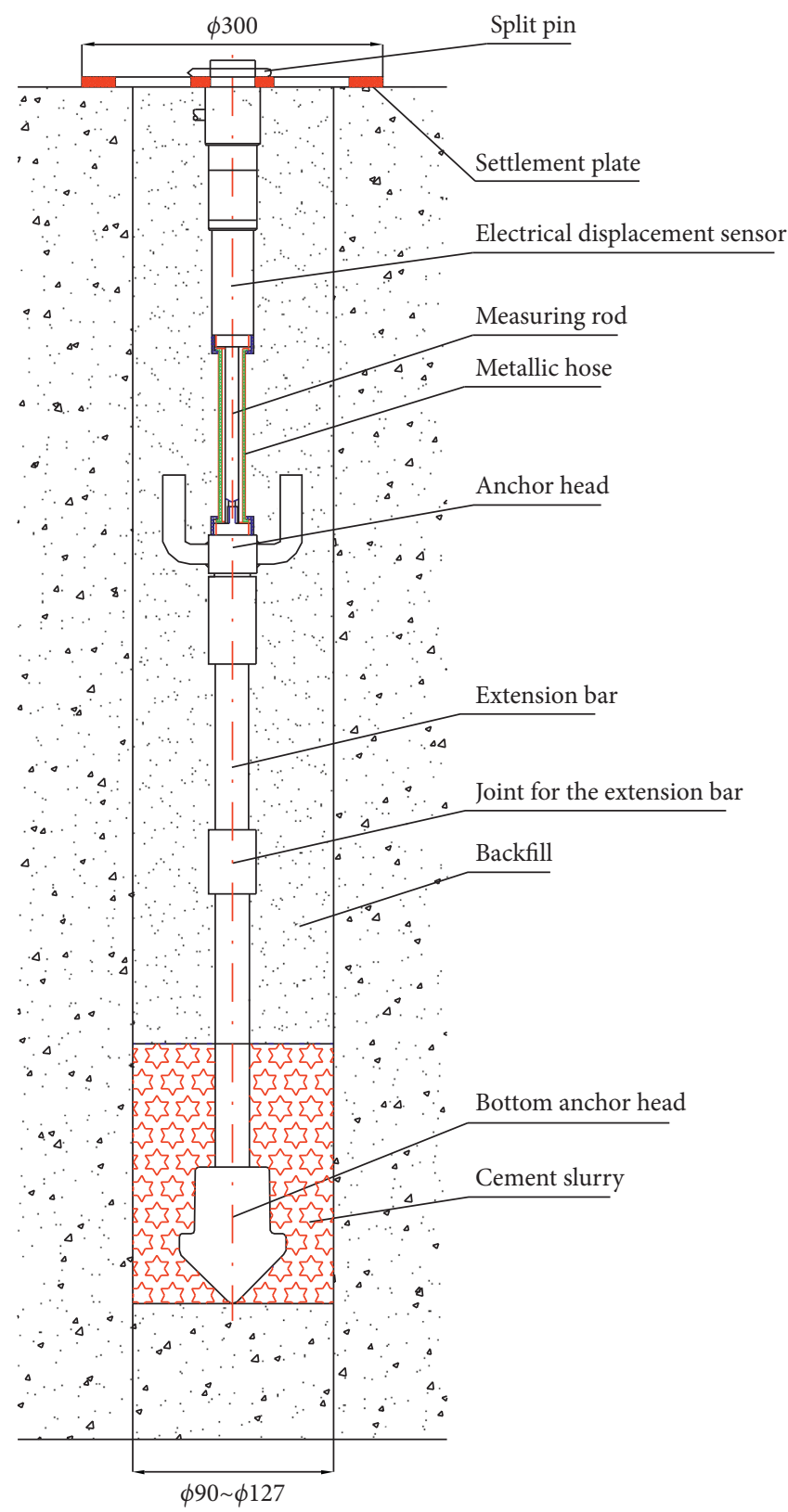

Figure 3: Schematic diagram of the single-point settlement meter.

and the traffic load was small without heavy vehicles. From December 2015 to February 2016, no settlement had been observed in the subgrade. However, the subgrade heave up to $3 \mathrm{~mm}$ was detected. It is because this area belongs to the seasonally frozen soil region, and the frozen soil during winter 


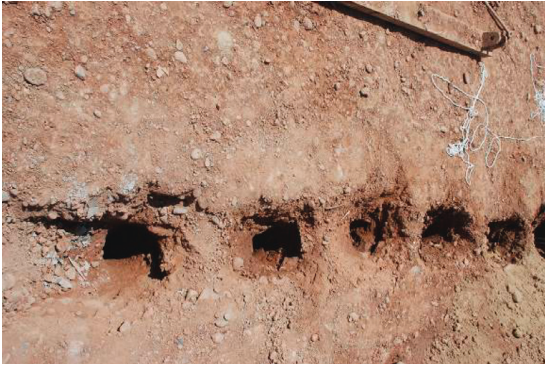

(a)

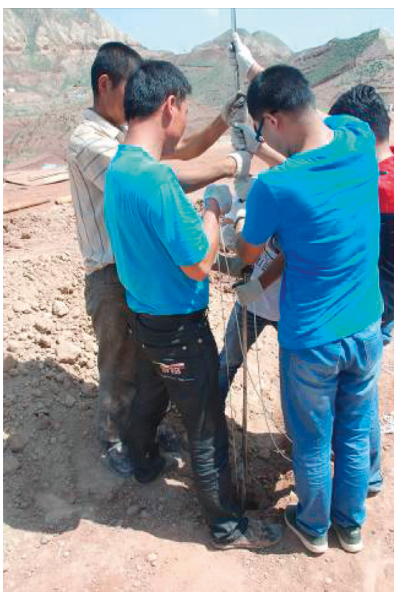

(c)

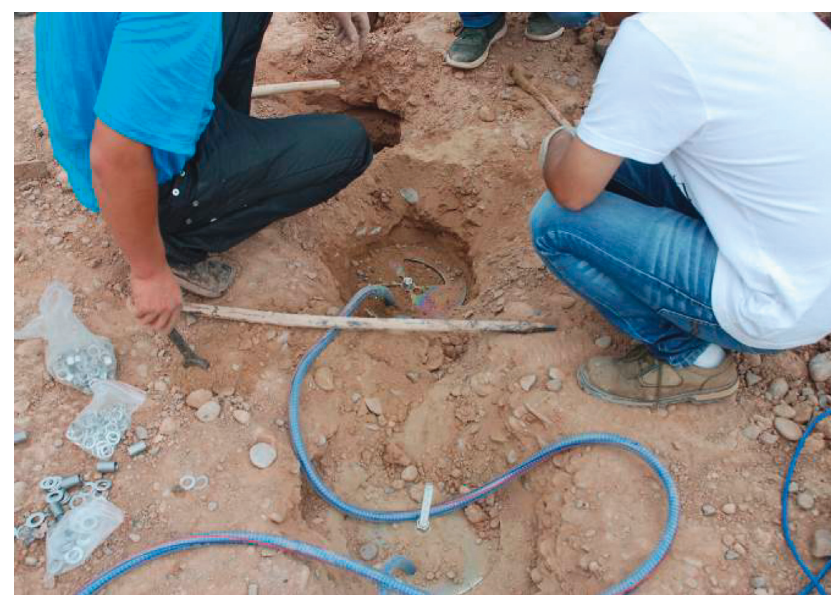

(d)

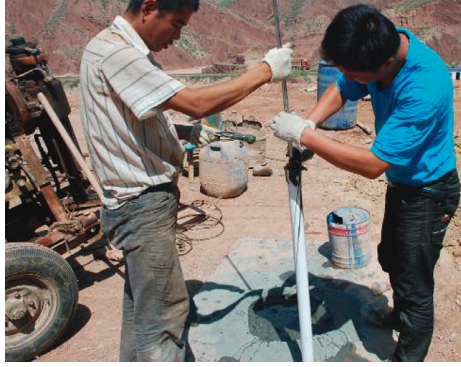

(b)

Figure 4: Setup of the single-point settlement meter and the automatic data collection system.

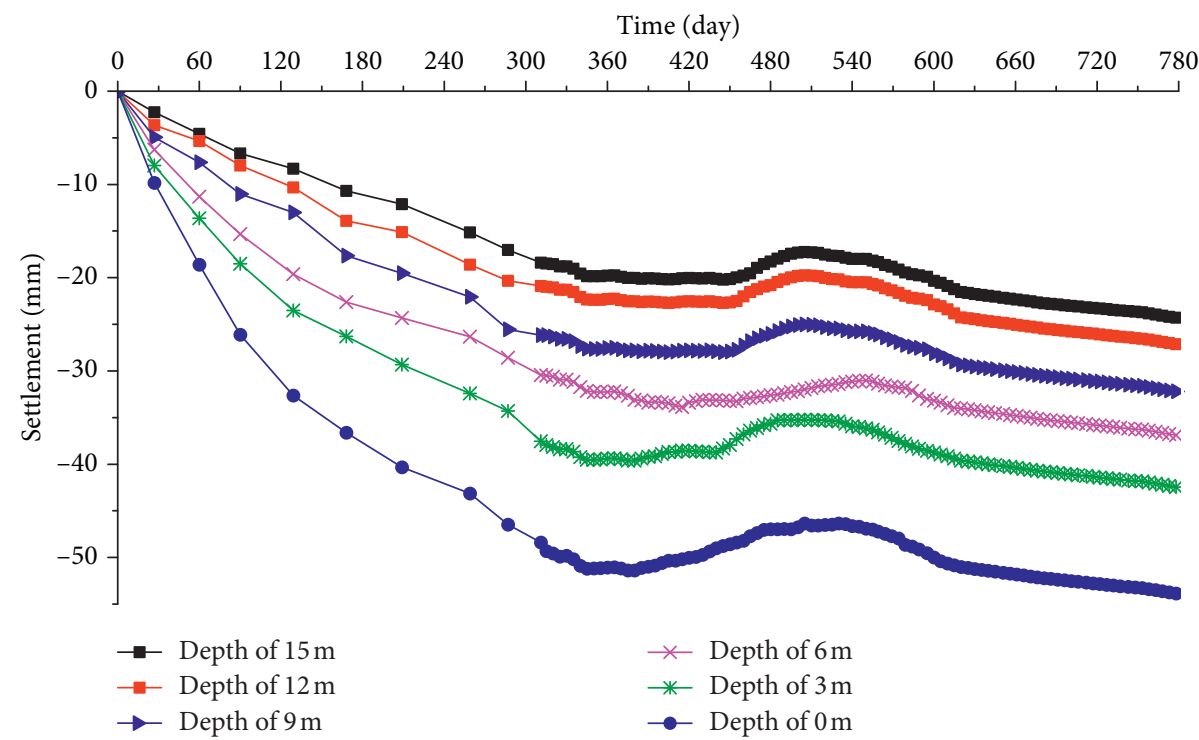

FIGURE 5: Variation of the settlement with time for different depths of the road shoulder.

leads to the ground heave [20]. By comparing Figures 5 and 6 , it can be identified that the settlement of the road shoulder is larger than that of the driveway. It is because the lateral restraint of the driveway is larger than that of the road shoulder. The traffic loading of the driveway is about three times than the overtaking lane. The road shoulder is only used to parking temporarily. According to the monitoring data for 26 months, the maximum settlement of the road shoulder on top of the subgrade is $53.86 \mathrm{~mm}$, while the maximum settlement of the driveway is $38.52 \mathrm{~mm}$. Larger settlement of the 


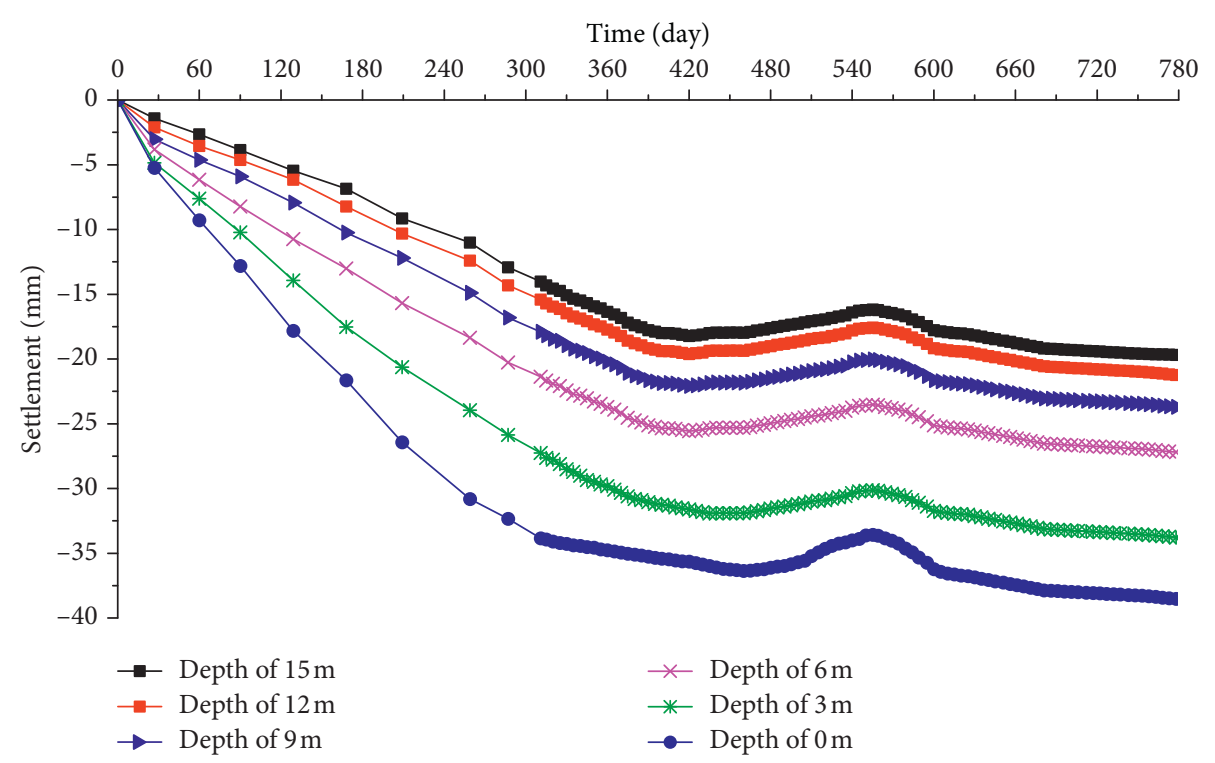

FIGURE 6: Variation of the settlement with time for different depths of driveway.

road shoulder can be attributed to the horizontal movement of the slope of the subgrade, which may be caused by the vehicle load (e.g., $[21,22])$. This finding is very important as the differential settlement may lead to cracks in the pavement.

3.2. Prediction Model for Subgrade Settlement. According to [22], the prediction methods for subgrade settlement can be characterized into three categories. The first is a theoretical method based on Terzaghi's one-dimensional consolidation theory. The secondary type of prediction is numerical analysis by adopting Biot's consolidation theory [23] and the soil constitutive model. The third one is to develop the relationship between settlement and time according to the measured data by curve fitting, which is adopted in this study. Hyperbolic, logarithmic, power, and exponential functions were used as the prediction models for the variation of settlement with time for both road shoulder and driveway, as shown in Figures 7 and 8. In the prediction models, $S_{t}$ is the predicted settlement (in $\mathrm{mm}$ ) while $t$ is the time (in day); $a, b$, and $c$ are the fitting parameters. For the hyperbolic model, the following type of the formula was adopted:

$$
S_{\mathrm{t}}=\frac{a}{t+b}-c
$$

For the logarithmic model, it is in the form of

$$
S_{\mathrm{t}}=a \ln (t+b)-c \text {. }
$$

The power function is shown as

$$
S_{\mathrm{t}}=a t^{b} \text {. }
$$

The exponential function is

$$
S_{\mathrm{t}}=a+b e^{c t} \text {. }
$$

It can be seen in Figures 7 and 8 that these four functions can give a reasonable prediction of the subgrade settlement, for both road shoulder and driveway. Among these four models for the road shoulder, the exponential function can give the best prediction of the subgrade settlement, with a correlation coefficient $R^{2}$ more than 0.977 for each depth of the subgrade. In terms of the driveway, both power function and exponential function show the precise prediction for the subgrade settlement.

In addition, if the settlement for each time point is divided by the settlement of 400 days, the normalized settlement curves can be found in Figure 9. It can be identified that, for both road shoulder and driveway, the normalized settlement for various depths falls in a narrow band. The exponential function can still be available as the prediction model for the normalized settlement. With the correlation coefficient higher than 0.97 , the fitting models for the normalized settlement of road shoulder and driveway are

$$
\begin{aligned}
\frac{S_{t}}{S_{400}} & =1.25656-1.23861 e^{-0.00421 t}, \\
\frac{S_{t}}{S_{400}} & =2.25814-2.24139 e^{-0.00147 t},
\end{aligned}
$$

where $S_{t} / S_{400}$ is the normalized settlement which equals to the measured settlement at any time point divided by the settlement of 400 days, while $t$ is the time (in days).

\section{Conclusion}

The settlement of the subgrade gradually increases with time up to two years, but most of the settlements would finish within one year. The increment rate of the settlement decreases with time. The settlement of the road shoulder is greater than that of the driveway. Hyperbolic, logarithmic, power, and exponential functions can be adopted to predict the subgrade settlement. And exponential function shows the very accurate prediction for the 


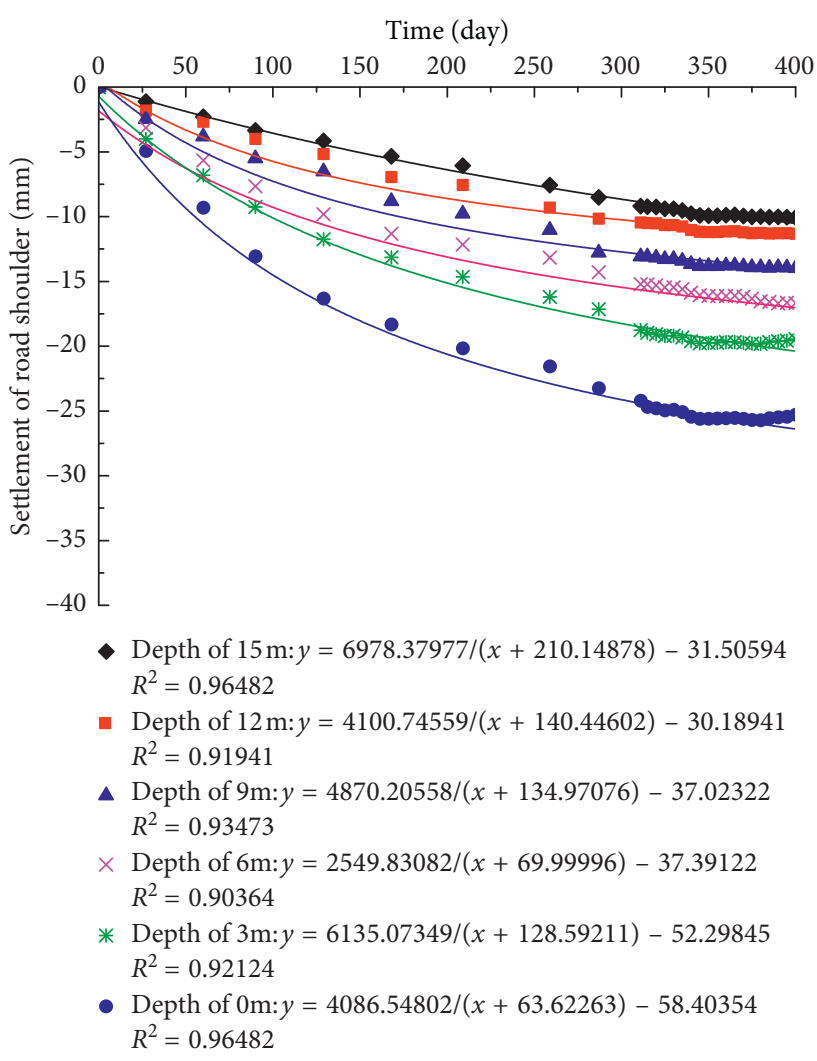

(a)

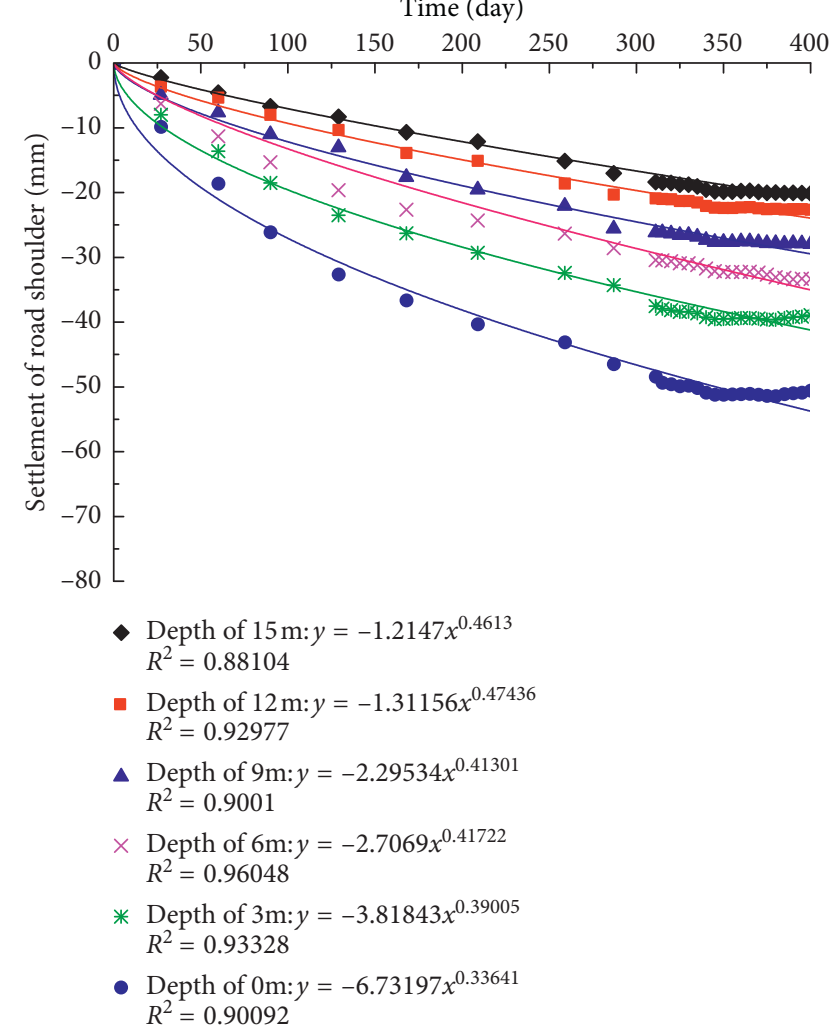

(c)

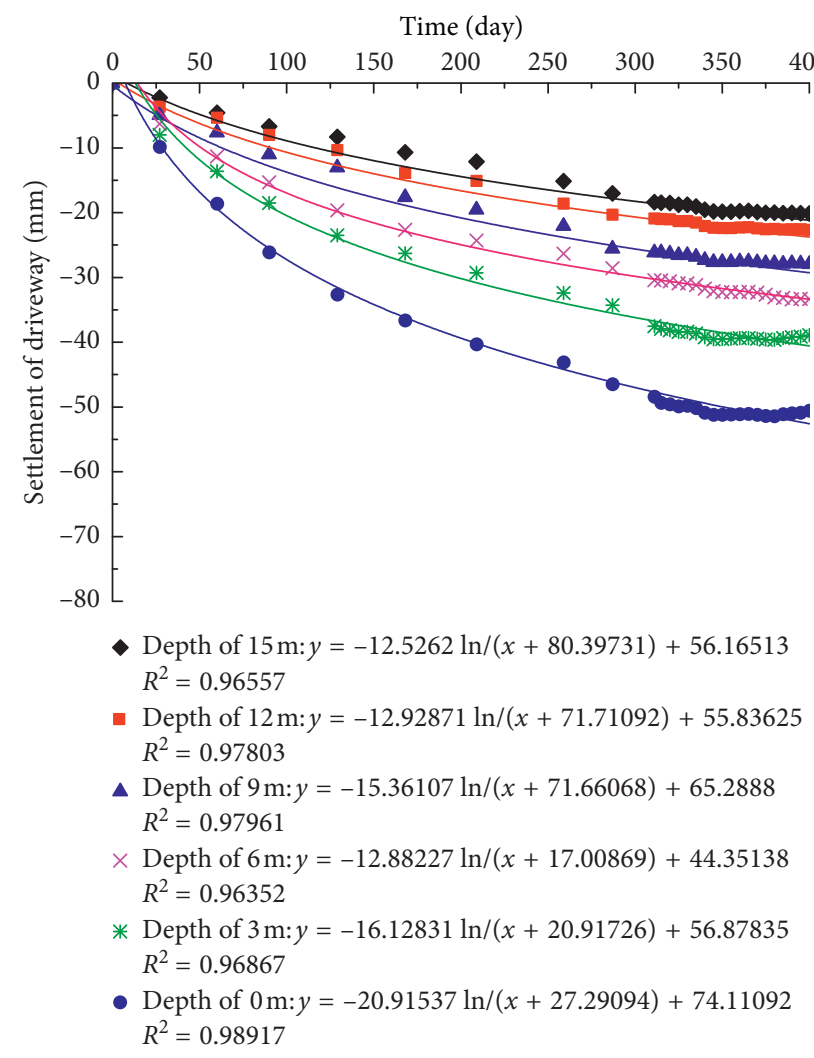

(b)

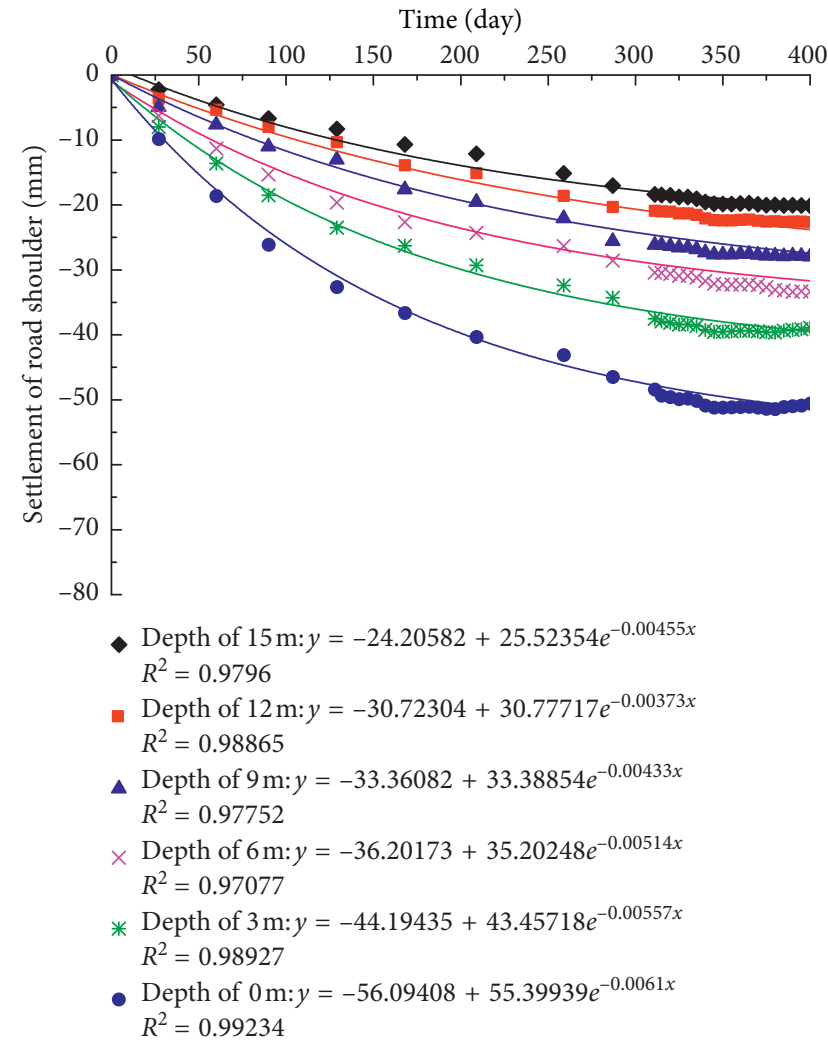

(d)

FIgURe 7: Prediction model for the settlement of the road shoulder: (a) hyperbolic function; (b) logarithmic function; (c) power function; (d) exponential function. 


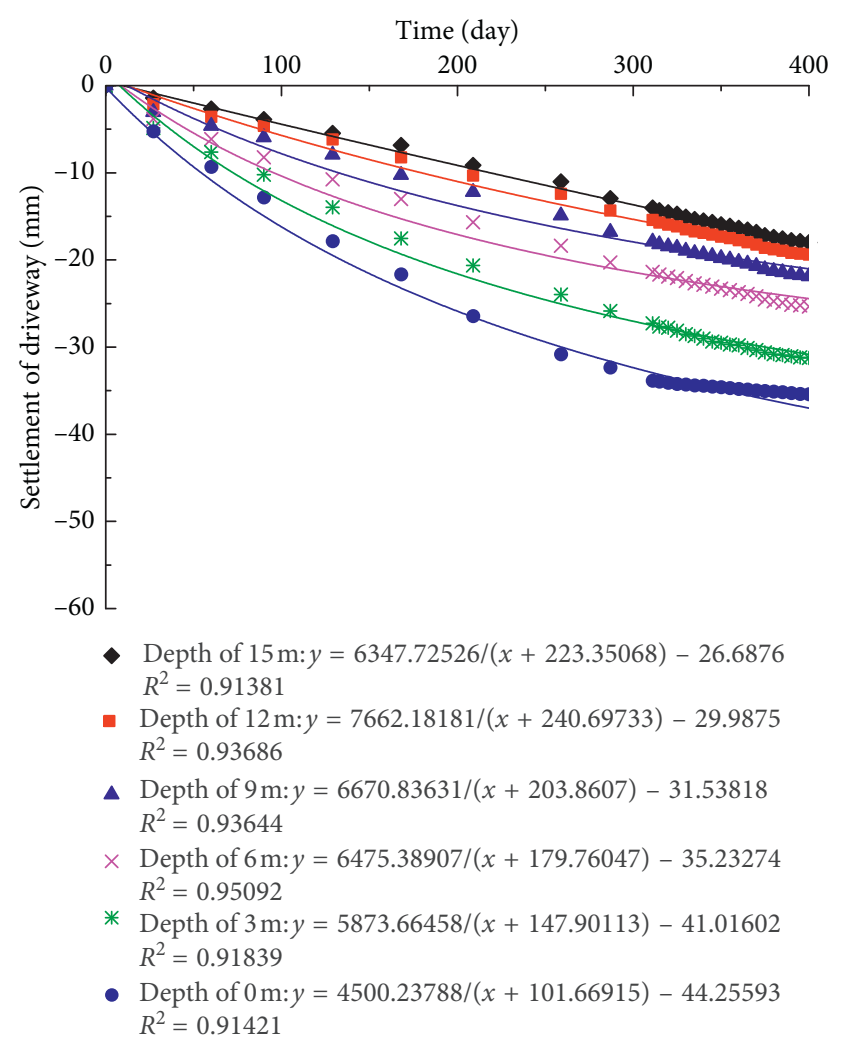

(a)

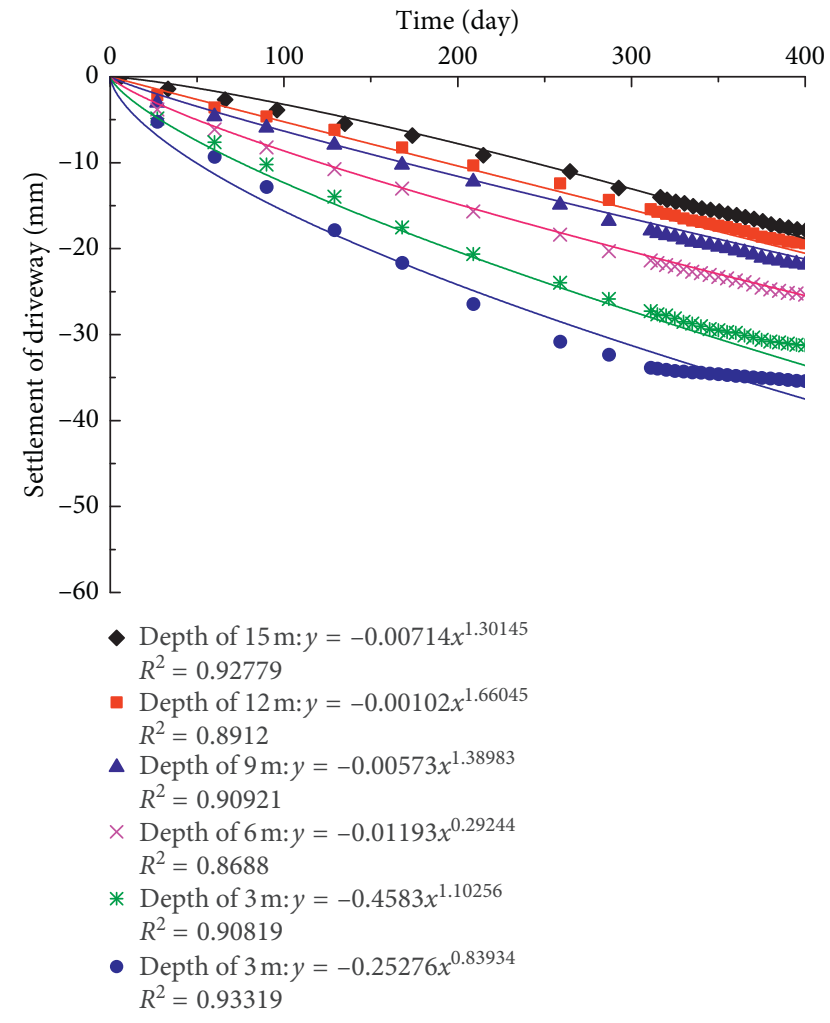

(c)

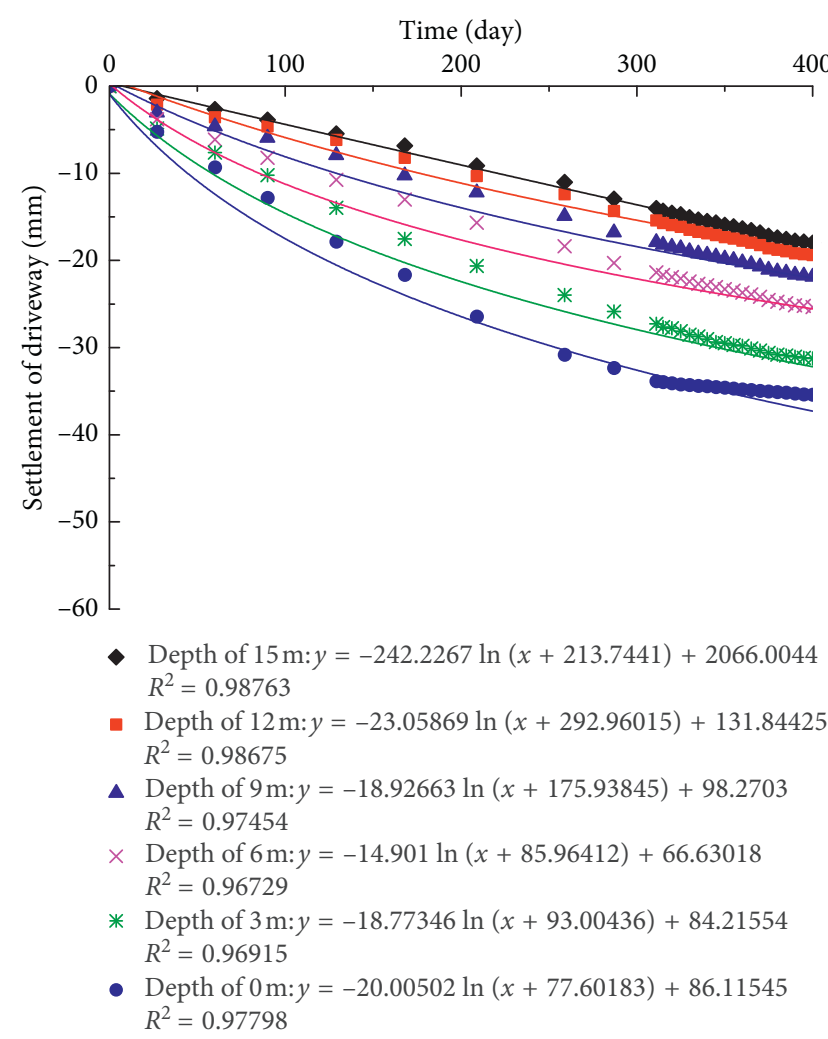

(b)

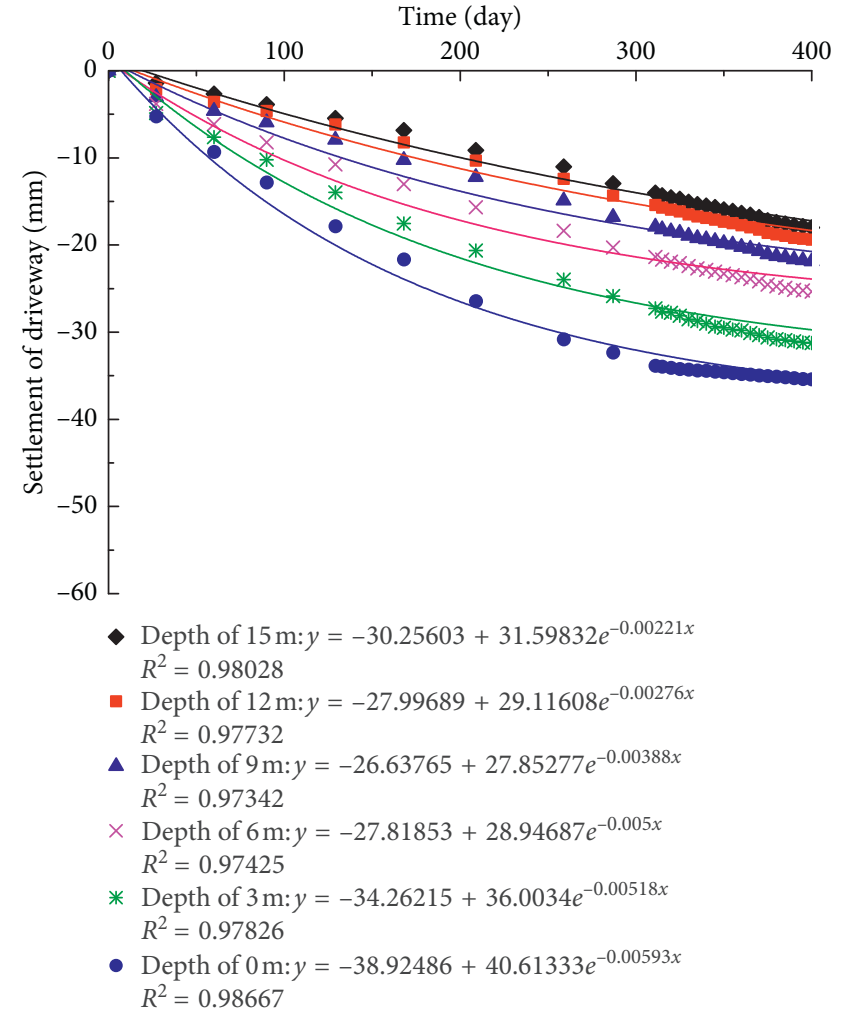

(d)

Figure 8: Prediction model for the settlement of driveway: (a) hyperbolic function; (b) logarithmic function; (c) power function; (d) exponential function. 


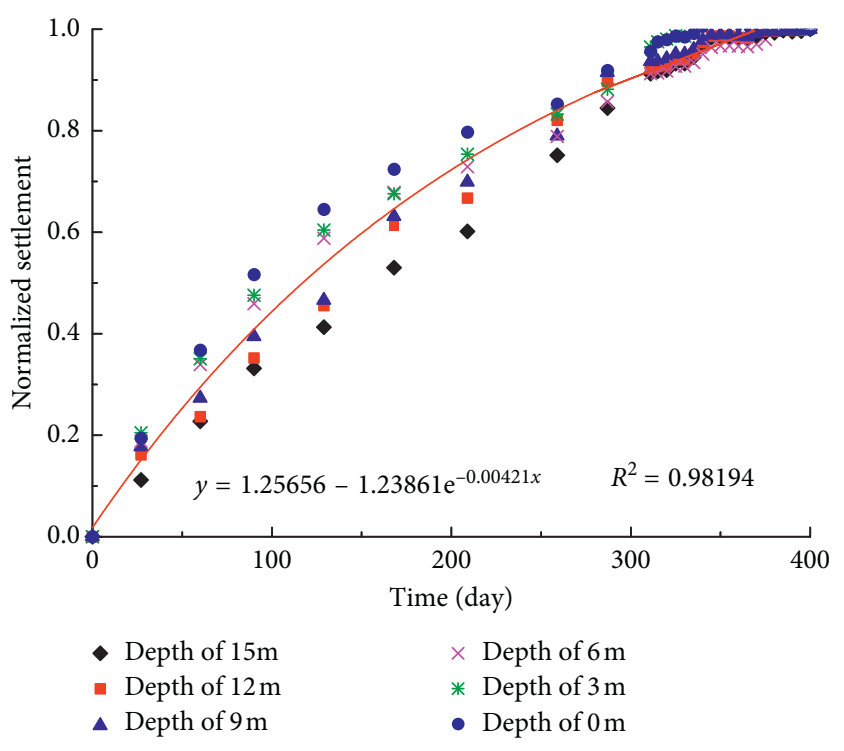

(a)

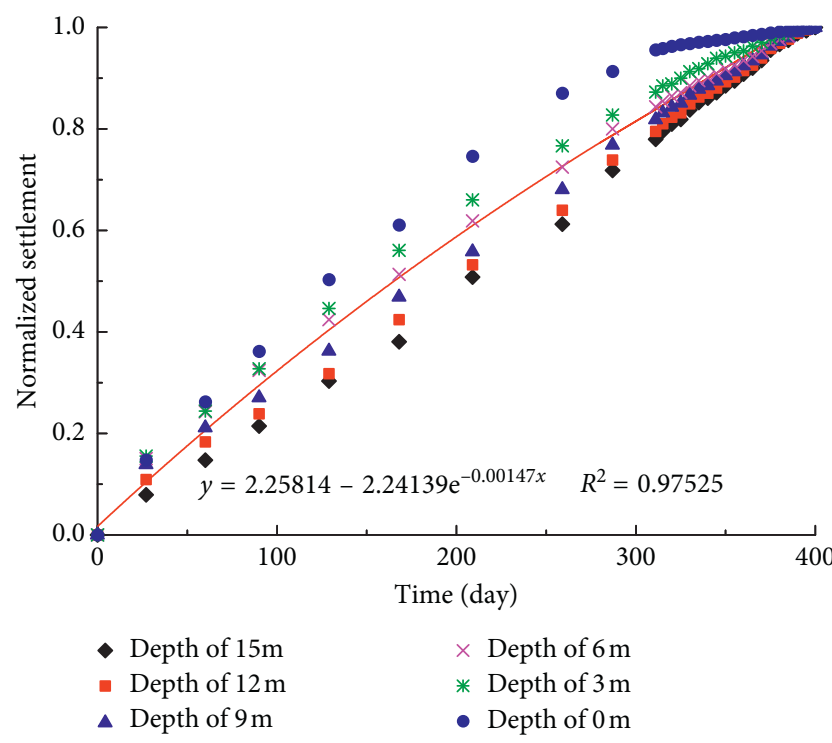

(b)

FIGURE 9: Variation of the normalized settlement with time: (a) road shoulder; (b) driveway.

subgrade settlement in both road shoulder and driveway. The normalized settlement can also be predicted well by the exponential function.

\section{Data Availability}

All the data used to support the findings of this study are included within the article.

\section{Conflicts of Interest}

The authors declare that they have no conflicts of interest.

\section{Acknowledgments}

This work was supported by the National Natural Science Foundation of China (Grant No: 51568044). The Program of Study Abroad for Middle Age and Young Scholars supported by Lanzhou University of Technology is also acknowledged.

\section{References}

[1] X. Cui, N. Zhang, S. Li, J. Zhang, and L. Wang, "Effects of embankment height and vehicle loads on traffic-load-induced cumulative settlement of soft clay subsoil," Arabian Journal of Geosciences, vol. 8, no. 5, pp. 2487-2496, 2015.

[2] L. Gao, Q. Zhou, X. Yu, and Z. Chen, "Analysis and model prediction of subgrade settlement for Linhai highway in China," Electronic Journal of Geotechnical Engineering, vol. 19, pp. 11-21, 2014.

[3] D. Chen, J. Ling, D. Li, and C. Zheng, "Monitoring and evaluating techniques of highway subgrade safety in the operation period," Road Materials and Pavement Design, vol. 18 , no. 3, pp. 215-225, 2017.

[4] A. Le Kouby, A. Guimond-Barrett, P. Reiffsteck, A. Pantet, J. F. Mosser, and N. Calon, "Improvement of existing railway subgrade by deep mixing," European Journal of Environmental and Civil Engineering, pp. 1-16, 2018.

[5] Z. Feng and W. Cao, "Observation and numerical analysis of settlement of high filled embankment on soft subgrade," Journal of Lanzhou University of Technology, vol. 39, no. 2, pp. 491-496, 2013, in Chinese.

[6] H. Jing, R. Su, and T. Su, "Study of settlement deformation prediction model of high subgrade," Rock and Soil Mechanics, vol. 28, no. 8, pp. 1762-1766, 2007, in Chinese.

[7] X. Sun, M. Zhao, K. Wang, and J. Xiang, "Numerical simulation on settlements of Changan comprehensive test track with high fill subgrade," Journal of Chongqing Jiaotong University (Natural Science), vol. 31, no. 2, pp. 257-260, 2012, in Chinese.

[8] T. F. Sonnemann, J. Ulloa Hung, and C. L. Hofman, "Mapping indigenous settlement topography in the Caribbean using drones," Remote Sensing, vol. 8, no. 10, p. 791, 2016.

[9] H. Wang, G. Feng, B. Xu et al., "Deriving spatio-temporal development of ground subsidence due to subway construction and operation in delta regions with PS-InSAR data: a case study in Guangzhou, China," Remote Sensing, vol. 9, no. 10, p. 1004, 2017.

[10] M. Yang, T. Yang, L. Zhang, J. Lin, X. Qin, and M. Liao, "Spatio-temporal characterization of a reclamation settlement in the Shanghai coastal area with time series analyses of X-, C-, and L-band SAR datasets," Remote Sensing, vol. 10, no. 2, p. 329,2018

[11] E. Díaz and R. Tomás, "A simple method to predict elastic settlements in foundations resting on two soils of differing deformability," European Journal of Environmental and Civil Engineering, vol. 20, no. 3, pp. 263-281, 2016.

[12] X. Kuang and D. Zou, "A new thought on prediction method for settlement after construction to high subgrade based on Compertz curve method," Highway Engineering, vol. 33, no. 1, pp. 127-129, 2008, in Chinese.

[13] L. Wang, B. Jin, and Y. Yang, "New model and method for forecasting post-construction settlement of loess-fill subgrades," Chinese Journal of Rock Mechanics and Engineering, vol. 26, no. 11, pp. 2370-2376, 2007, in Chinese. 
[14] M. A. Al-Shamrani, "Applying the hyperbolic method and $\mathrm{C} \alpha / \mathrm{Cc}$ concept for settlement prediction of complex organicrich soil formations," Engineering Geology, vol. 77, no. 1, pp. 17-34, 2005.

[15] J. Jiang, Q. Chen, and S. Nimbalkar, "Field data based method for predicting long-term settlements," American Journal of Engineering and Applied Sciences, vol. 9, no. 3, pp. 466-476, 2016.

[16] K. Terzaghi, R. B. Peck, and G. Mesri, Soil Mechanics in Engineering Practice, John Wiley \& Sons, Hoboken, NJ, USA, 1996.

[17] R. J. Chenari and N. S. Noori, "Uncoupled consolidation analysis of clay deposits with linearly varying characteristics with depth," Iranian Journal of Science and Technology, Transactions of Civil Engineering, vol. 41, no. 1, pp. 49-53, 2017.

[18] D. G. Fredlund and H. Rahardjo, Soil Mechanics for Unsaturated Soils, John Wiley \& Sons, Hoboken, NJ, USA, 1993.

[19] M. J. Olsen, J. Wartman, M. McAlister et al., "To fill or not to fill: sensitivity analysis of the influence of resolution and hole filling on point cloud surface modeling and individual rockfall event detection," Remote Sensing, vol. 7, no. 9, pp. 1210312134, 2015.

[20] F. Yu, J. Qi, Y. Lai et al., “Typical embankment settlement/ heave patterns of the Qinghai-Tibet highway in permafrost regions: formation and evolution," Engineering Geology, vol. 214, pp. 147-156, 2016.

[21] X. Chu, L. Li, and L. Kong, "Sensitivity study of local average size on the failure probability of spatially variable slope stability," Iranian Journal of Science and Technology, Transactions of Civil Engineering, vol. 41, no. 2, pp. 167-173, 2017.

[22] L. Tang, P. Qiu, C. M. Schlinger, G. Yang, and W. Ye, "Analysis of the influence of vehicle loads on deep underground excavation-supporting structures," Iranian Journal of Science and Technology, Transactions of Civil Engineering, vol. 40, no. 3, pp. 209-218, 2016.

[23] M. A. Biot, "General theory of three-dimensional consolidation," Journal of Applied Physics, vol. 12, no. 2, pp. 155-164, 1941. 


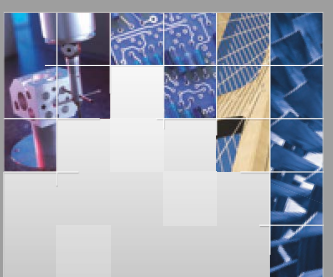

\section{Enfincering}
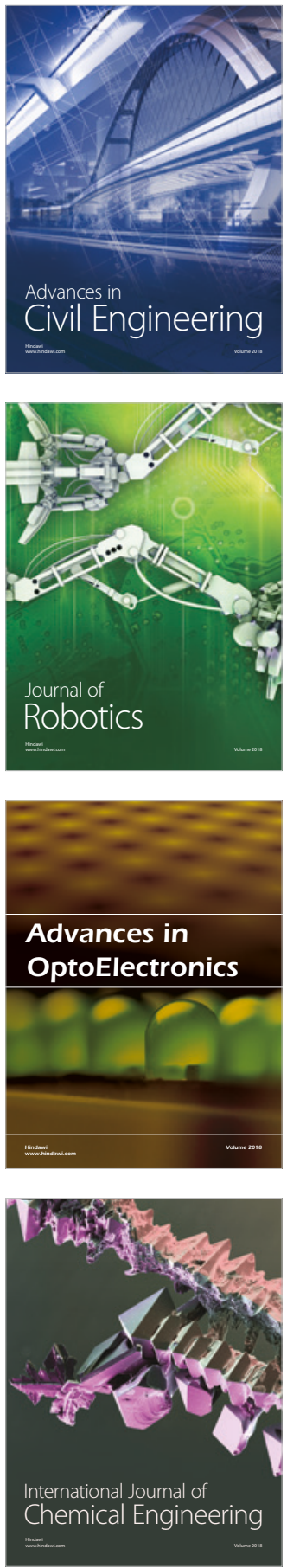

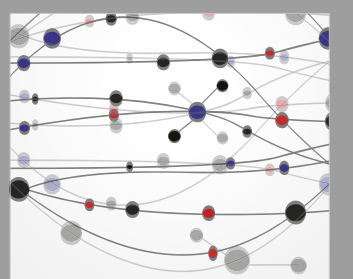

\section{Rotating \\ Machinery}

The Scientific World Journal

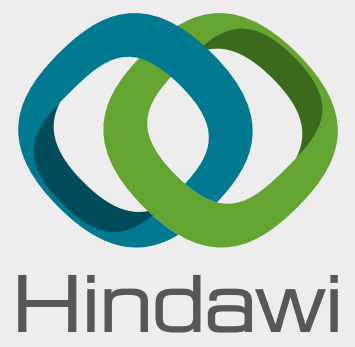

Submit your manuscripts at

www.hindawi.com
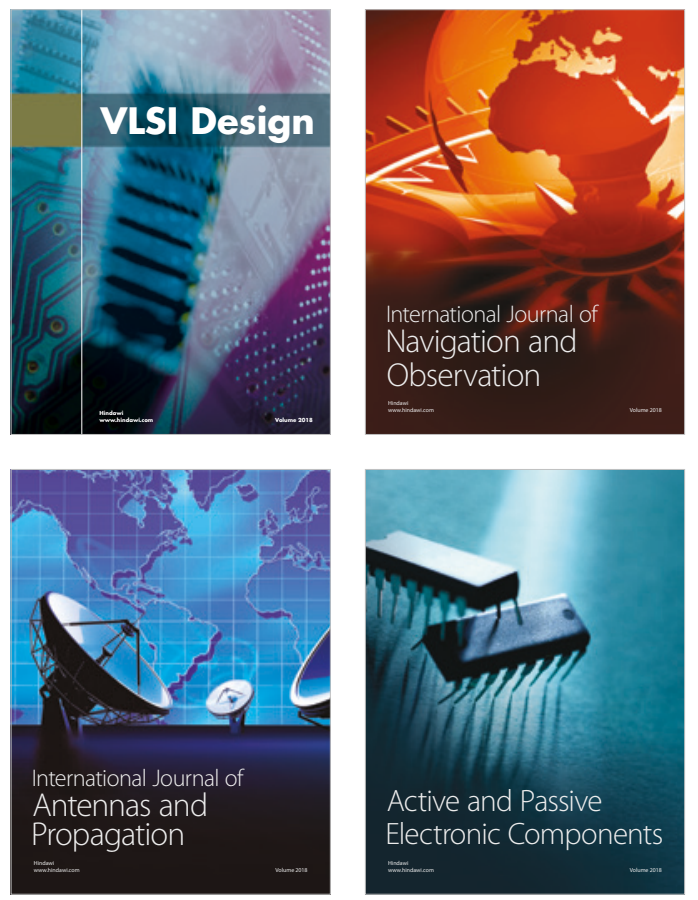
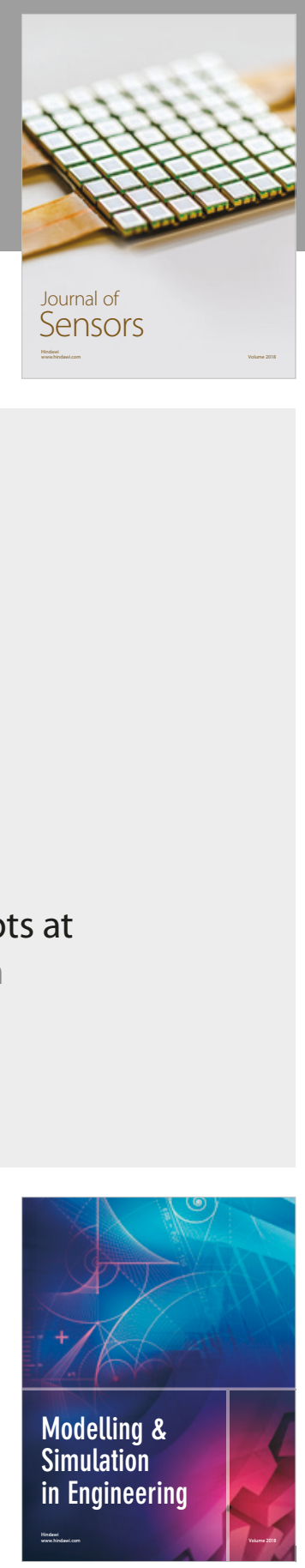

\section{Advances \\ Multimedia}
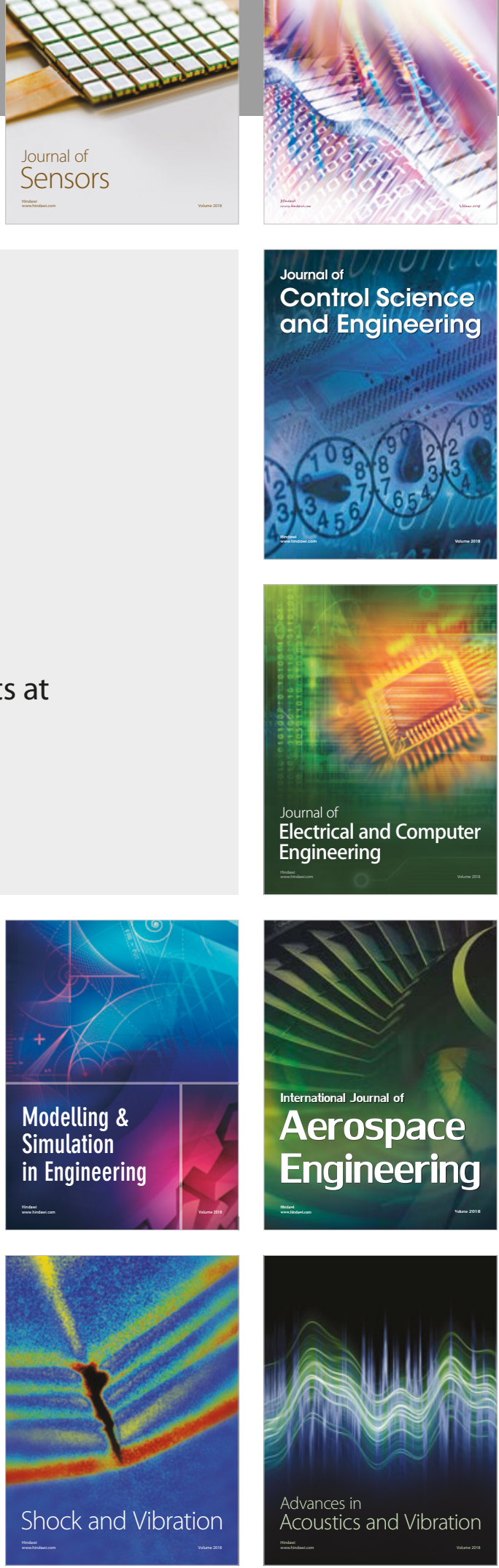